\title{
Correction to: The Student Resilience and Well-Being Project: Opportunities, Challenges, and Lessons Learned
}

\section{Rick H. Hoyle ${ }^{1}$ (D) Molly S. Weeks ${ }^{2}$ (D) The Student Resilience and Well-Being Project Research Group}

Accepted: 18 August 2021 / Published online: 7 September 2021

(c) The Author(s), under exclusive licence to Springer Nature Switzerland AG 20212021

\section{Correction to: International Journal of Community Well-Being https://doi.org/10.1007/s42413-021-00138-2}

In this article The Student Resilience and Well-Being Project Research Group ${ }^{3}$ members are (in alphabetical order by institution and last name) Lauren A. Stutts (Department of Health and Human Values, Davidson College); Steven R. Asher, Rick H. Hoyle, Mark R. Leary, Timothy J. Strauman, and Molly S. Weeks (Department of Psychology \& Neuroscience, Duke University); Kerstin K. Blomquist, Beth A. Pontari, and Cinnamon A. Stetler (Department of Psychology, Furman University); and Debra F. Terrell (Department of Social and Behavioral Sciences, Johnson C. Smith University)

The original article has been updated.

Publisher's Note Springer Nature remains neutral with regard to jurisdictional claims in published maps and institutional affiliations.

The original article can be found online at https://doi.org/10.1007/s42413-021-00138-2.

Rick H. Hoyle

rhoyle@duke.edu

1 Department of Psychology \& Neuroscience, Duke University, Durham, NC 27708-0086, USA

2 Office of Undergraduate Education, Duke University, Durham, NC 27708-0024, USA 